\title{
Characterization of dilated cardiomyopathy using tissue phase mapping and extracellular volume measurement
} Lewis C Sommerville $^{1 *}$, Jacob Fluckiger ${ }^{1}$, Michael Markl ${ }^{1}$, Jeremy Collins ${ }^{1}$, Shivraman Giri², James Carr ${ }^{1}$,
Keyur Parekh', Amita Goyal ${ }^{1}$

From 16th Annual SCMR Scientific Sessions

San Francisco, CA, USA. 31 January - 3 February 2013

\section{Background}

Non-ischemic dilated cardiomyopathy (DCM) is a relatively common cause of left ventricular dysfunction. Microscopic scar may be a cause of regional and global left ventricular dysfunction in DCM patients. The aim of this study was to evaluate changes in regional myocardial structure, function, and dyssynchrony using a novel noninvasive MR imaging protocol.

\section{Methods}

Eleven patients with suspected non-ischemic cardiomyopathy underwent cardiac MRI (CMR) on a $1.5 \mathrm{~T}$ magnet (Magnetom Avanto or Aera, Siemens Healthcare, Erlangen,
Germany). In addition to the conventional CMR viability protocol, patients underwent both tissue phase mapping (TPM) and T1 mapping with a modified look-locker inversion recovery (MOLLI) technique pre and between 10 and 25 minutes post $0.2 \mathrm{mmol} / \mathrm{kg}$ adminstration of an extracellular gadolinium agent. These sequences were performed through the left ventricle in the short axis orientation at basal, mid-chamber, and apical levels. The hematocrit was collected within 48 hours of the CMR to calculate segmental ECV values as described by Kellman, et al., as a marker of microscopic fibrosis. TPM analysis was used to determine the degree of segmental wall motion abnormality. Radial, longitudinal and absolute velocities
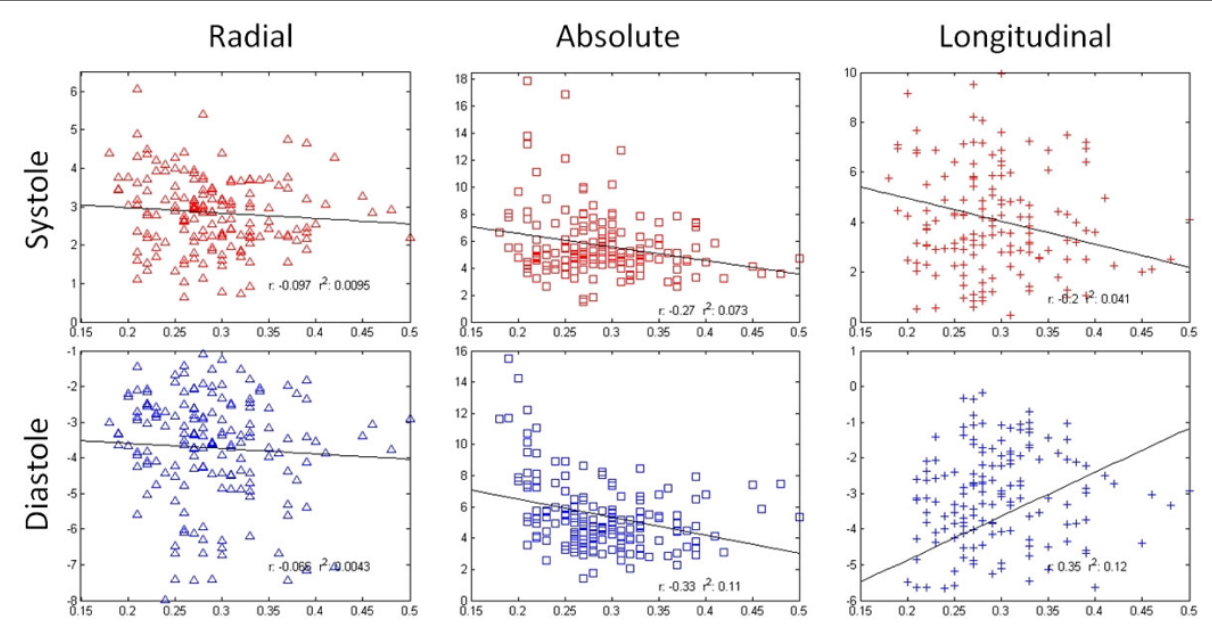

Figure 1 Distribution of myocardial velocities in systole and diastole (radial, absolute, and longitudinal) by ECV fraction. As ECV fraction increases there are reduced longitudinal and absolute myocardial velocites, while little change is observed in radial myocardial velocities.

${ }^{1}$ Radiology, Northwestern Memorial Hospital, Chicago, IL, USA

(C) 2013 Sommerville et al; licensee BioMed Central Ltd. This is an Open Access article distributed under the terms of the Creative Commons Attribution License (http://creativecommons.org/licenses/by/2.0), which permits unrestricted use, distribution, and reproduction in any medium, provided the original work is properly cited. 


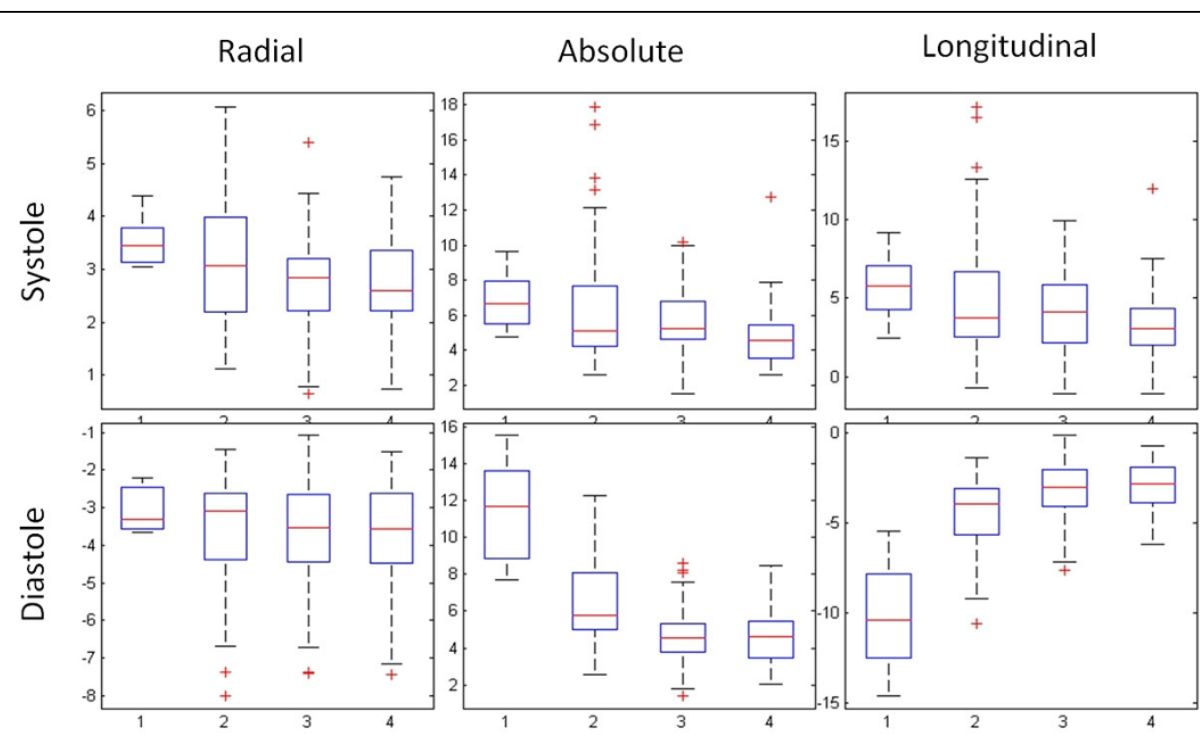

Group $1($ ecv<0.21) $-\mathrm{n}=7$ Group $2(\mathrm{ecv}>=0.21 \&<0.26)-\mathrm{n}=39$

Group 3 (ecv>=0.26 \& $<0.31) n=63$ Group $4(e c v>=0.31)-n=58$

Figure 2 Myocardial segments were grouped into normal (group 1), borderline normal (group 2), borderline abnormal (group 3), and abnormal (group 4) by ECV values as noted above.

were measured from the TPM images. Short axis slices were analysed on a segmental basis using the AHA 16 segment model. Segments were classified into four ECV subgroups as detailed in Figure 1; TPM results were compared by ECV subgroup.

\section{Results}

Longitudinal and absolute peak systolic and diastolic velocities were reduced in segments with increased fibrosis (Figure 2). These trends are also well-illustrated by ECV subgroup analysis (Figure 1). Most pronounced changes were found for diastolic function with substantial reductions of longitudinal peak velocities $(r=0.35)$. There was little change between radial peak systolic and diastolic velocity with increasing fibrosis in this cohort.

\section{Conclusions}

Our preliminary findings suggest a myocardial structurefunction relationship linking myocardial fibrosis with altered myocardial function at a segmental level. Recruitment is ongoing to validate our results in a larger patient cohort.

Kellman et al.: J Cardiovasc MR 2012, 14:63,64

\section{Funding}

Not funded.

\section{Author details}

'Radiology, Northwestern Memorial Hospital, Chicago, IL, USA. ${ }^{2}$ Siemens Healthcare, Chicago, IL,USA.

Published: 30 January 2013

doi:10.1186/1532-429X-15-S1-P105

Cite this article as: Sommerville et al:: Characterization of dilated cardiomyopathy using tissue phase mapping and extracellular volume measurement. Journal of Cardiovascular Magnetic Resonance 201315 (Suppl 1):P105.
Submit your next manuscript to BioMed Central and take full advantage of:

- Convenient online submission

- Thorough peer review

- No space constraints or color figure charges

- Immediate publication on acceptance

- Inclusion in PubMed, CAS, Scopus and Google Scholar

- Research which is freely available for redistribution

Submit your manuscript at www.biomedcentral.com/submit
C Biomed Central 